\title{
UM PROBLeMA DE ENFERMAGEM - A LIPODISTROFIA INSULÍNICA
}

\author{
* Reggia Celeste da Cruz Borges \\ * Clenir Bastos Marra Pereira \\ ** Lindalva Garcia Segura \\ **: Lucia da Conceição Costa Fraṇ̣a
}

\begin{tabular}{l|l} 
& $\mathrm{RBEn} / 11$ \\
\hline
\end{tabular}

BORGES, R.C.C. e Colaboradoras - Um problema de enfermagem - A lipodistrofia insulínica. Rev. Bras. Enf.; DF, 31 : 252-258, 1973.

\section{INTRODUÇÃO}

A insulinoterapia subcutânea, desde a sua descoberta em 1921, trouxe para o diabético, inúmeros benefícios, apesar de terem surgido com seu uso várias complicações e efeitos colateriais. A lipodistrofia insulínica é apontada dentre estas, como a complicação mais freqüente. a casuística aponta uma incidência independente do tipo de insulina usada. A idade e o sexo são variáveis inexpressivas apesar de referência na literatura a cerca de maior aparecimento das lipodistrofias no sexo feminino. Quanto à dosagem, os pacientes que recebem doses mais elevadas e concentradas por longo tempo, também são referidos como os que têm maior incidência das complicaçōes. A literatura tem uma caracterís - ca comum na referência: o uso repetido de aplicaçōes insulínicas no mesmo lo. cal. No presente, este problema ainda ocorre, e seu tratamento segundo a bibliografia é o preventivo.

Outros fatcres que vêm corroborar quanto ao tempo e forma sutil do desenvolvimento da lipodistrofia é que geralmente os pacientes só se apercebem da lesão quando esta já atingiu proporçōes irreversíveis. Nem a fisioterapia, as hialozimas, nem os hormônios, lograram resultados alvissareiros.

Tendo em vista estes aspectos e mais o que observou-se no cotidiano é que os autores resolveram efetuar o presente estudo. Verificando-se a inexístência, mesmo nos serviços específicos, de instrumentos controladores do rodízio do local da aplicação insulínica, sentiu-se

- Livre Docente - Chefe do Departamento.

* Auxiliar de Ensino.

*** Professor Assistente. 
BORGES, R.C.C. e Colaboradoras - Um problema de enfermagem - A lipodistrofia insulínica. Rev. Bras. Enf.; DF, 31 : 252-258, 1978.

a necessidade de uma atualização por parte das enfermeiras(os) para sensibilizarem-se da necessidade de implementar no sistema de atividade de enfermagem, um instrumento que avalie $e$ controle o rodízio do local da aplicação na terapêutica insulínica.

O propósito do presente trabalho é despertar o interesse dos enfermeiros para o problema da lipodistrofia insulínica, adotando um método próprio de ação preventiva junto ao paciente. Este ensaio preliminar, visa sobretudo, verificar o sistema de controle utilizado pelo enfermeiro na avaliação do rodízio da área e local na insulimoterapia subcutânea, e identificar lesōes físicas no paciente diábetico, no local da aplicação da insulina. Para tanto, elaborou-se um estudo prévio da situação de enfermagem no que se refere a este assunto, considerando-se a limitação da literatura, sob o ponto de vista de enfermagem.

\section{LITERATURA}

Logo após o início da insulina no tratamento da diabetes Mellitus, começou a a surgir as primeiras complicaçōes da terapêutica. Com o aumento da sua utilização multiplicaram-se estas ocorrêrcias: manifestaçōes alérgicas, insulinoresitência, lipodistrofia-insulínica abscesso.

Com o emprego sistematizado das váriais composiçōes da insulina começam a surgir vários efeitos colaterais entre eles nos interessa particularmente, a lipodistrofia insulinica. A lipodistrofia, segundo a literatura é a complicação mais freqüente da terepêutica insulínica e se caracteriza por "distúrbios da deposição do tecido subcutâneo, nos pontos onde a isulina é aplicada, sobretudo quando as injeçōes são feitas repetidamente na mesma área da pele". Outras referências às características da complicaçāo, descrita como lipodistrofia "depressão local que muitas vezes é tāo profunda que deixa visível o relevo muscular subjacente, denotando desaparecimento do tecido adiposo subcutâneo naquela área.

MANHAES refere litpodistrofia como "alteração do tecido adiposo no local das injeçōes de insulina".

Verificamos como foi descrito que é característica comum nas complicaçōes lipodistróficas o aparecimento de lesão após aplicações insulínicas, e que elas têm quase sempre a mesma aparência. ARDUINO ressalva, acrescentando ao que já expomos: - "a lipodistrofia é progressiva, notando-se imediatamente o desaparecimento da gordura subcutânea. A pele se apresenta em depressãj tanto em extensão como em profundidade desde pequenas placas, a profun. das escavaçoes, intensamente deformantes", mais adiante, ainda aponta: "forma de tumores arredondados indolores, bem delimitados ou difusos"... "é necessário saber identificá-los, porquanto nem sempre se apresentam uniforme, por vezes acontece de coexistirem duas lesōes no mesmo local"... "encontram-se com maior freqüência lesões localizadas nas áreas de maior incidência de aplicaçōes de insulina: coxas, nádegas, deltóides, face externa de antebraço e abdome"... "para melhor estudos da lipodistrofia, encontram-se poucos casos notificados, e os autores concluem não haver cuidados permanentes na observação dos pacientes para maiores registros científicos".

Não há terapêutica eficaz. As lesōes são irreversiveis. O ideal, a literatura afirma é a PREVENÇÃO.

Segundo ARDUINO foram tentados tratamentos com hormônios, hialozimas, fisioterapia, sem resultados satisfatórios Só cirurgia plástica reparadora resolve em parte, o problema. Entre as medidas preventivas diversos autores recomendam que não sejam feitas injeçōes freqüentes numa mesma área e se isto for necessário, recomenda-se que se obedeça o mínimo de $2 \mathrm{~cm}$ de espaço da in- 
BORGES, R.C.C. e Colaboradoras - Um problema de enfermagem - A lipodistrofia insulínica. Rev. Bras. Enf.; DF, 31 : 252-258, 197 i.

jeção anterior, seguir o roteiro do rodizio procurando sempre registrar o local para que haja controle e aplicar as doses mais profundas quando as insulinas forem mais concentradas.

BROWN e REDMAN enfantizam a necessidade da enfermeira(o) educar ao paciente na auto aplicação insulínica e controlar as áreas e locais da aplicação. este treinamento, eles recomendam que deve ser desenvolvido na unidade de internação e no ambulatório.

$\mathrm{Na}$ literatura foram encontradas algumas sugestões tais como gráficos, figuras, mapas que segundo autores ajudariam no controle e rodízio do local insulínico. A estes instrumentos os auto.. res do presente trabalho acrescentaram outros e recomendam seu uso para o rodízio no local de aplicação insulínica.

\section{METODOLOGIA DO ESTUDO}

\subsection{Campo de Pesquisa}

O estudo foi realizado em unidades de internação de Clínica Médica de hospitais gerais e especializadas no Municipio do Rio de Janeiro.

A escolha recaiu sobre estas instituições em virtude de no momento, representarem a maior oferta de assistência médica ao paciente diabético.

\subsection{Amostra}

Selecionou-se quarenta e três pacientes diabéticos hospitalizados, de ambos os sexos, adultos, submetidos ao tratamento insulínico subcutâneo e dezesseis enfermeiras que assitissem a paciente diabéticos nas referidas unidades durante o periodo de três semanas.

Quanto ao paciente:

- Em relação ao sexo, encontrou-se $71,5 \%$ de casos de lipodestrofia no sexo masculino e $28,5 \%$ no sexo feminino.

- Em relação a faíxa etária, $43 \%$ de 21 até 40 anos; de 41 até 50 anos, e mais do que 50 anos, encontrou-se o percentual de $28,5 \%$ respectivamente.

\subsection{Método}

Para alcançar os objetivos propostos foram utilizados questionários e formulários com perguntas fechadas a fim de fazer o levantamento dos dados (Anexo).

Os métodos utilizados foram: observação direta através exame do local de aplicação, investigação social e análise de documento onde procurou-se identificar se é observado pela enfermeira(o) o rodízio da área e local de aplicação de insulina; se são adotadas medidas de controle e avaliação de terapêutica e também verificou-se o nível de conhecimento acerca da complicação lipodistrófica.

Para aplicação do questionário foi constituída uma equipe de quatro professores do Departamento de Enfermagem Médico Cirúrgica para orientar no preenchimento do questionário e elucidar as dúvidas.

Para padronização do estudo estabeleceu-se os seguinte princípios:

- Que fossem pacientes diabéticos internados na Unidade de Clínica Médica.

- Que fossem pacientes diabéticos em uso de terapêutica da insulina subcutânea.

- Que os aplicadores do questionário fossem os mesmos para os formulários.

\subsection{Critério de Avaliação}

Para padronizar a análise qualitativia do método utilizado para controle dos locais de aplicação da insulinoterapia subcutânea, estabeleceu-se os seguintes critérios:

- Suficiente: Acima de $\mathbf{7 0 \%}$, as unidades que aplicassem um instrumento avaliador e controlador e que fosse ob. servado o rodízio das áreas de aplicação.

- Insuficiente: de $50 \%$ a $70 \%$ as Unidades nas quais o controle e avaliação fossem na forma de supervisão. 
BORGES, R.C.C. e Colaboradoras - Um problema de enfermagem - A lipodistrofia insulínica. Rev. Bras. Enf.; DF, $31: 252-258,1978$.

- Deficiente: abaixo de 50\%, nas unidades que não tivessem um instrumento de registro para controie e avaliação.

Os dados foram apurados manualmente; trabalhados e submetidos à análise estatística.

3.5. Conceituação de termos

- Critério: normas estabelecidas para o julgamento.

- Chefe de Setor: Enfermeiro responsável pela equipe de enfermagem no setor.

- Chefe de Unidade: Enfermeiro responsável pela assistência de enfermagem na Unidade de Internação.

- Chefe de Serviço: Enfermeiro responsável pelo Serviço de Enfermagem.

- Enfermeira de Cabeceira: Enfermeira que presta assistência de enfermagem direta aos pacientes internados na Unidade de Internação.

- Folha única: instrumento destinados ao registro da prescrição médica e execução dos cuidados de enfermagem.

- Hospital Especializado - Instituição que atende somente clientela cuja patologia é específica.

- Mapa Insulínico: impresso utilizado para orientação do controle das áreas $€$ locais de aplicação de insulina.

- Mistura Insulínica, administração da Insulina Regular e Insulina Protanina Zinco.

- Prescrição: Enumeração por escrito dos cuidados a serem prestados ao paciente.

- Registro; todo e qualquer materiai onde salvo qualquer forma, seres humanos gravam informação que possam ser interpretadas.

- Rodízio: alternância de locais ou áreas de aplicação.

- Sistema: Partes de um conjunto combinados ou coordenados entre si, tendo em vista certo resultado.
- Supervisora: Enfermeira que orienta e controla as Unidades de Enfermagem.

\section{RESULTADOS E COMENTÁRIOS}

Nos dados coletados através os questionários a plic ados nos enfermeiros para identificar o problema, evidenciouse os seguintes resultados:

Em referência a região acometida, constatou-se 0 maior percentual no "não observado" isto é $44 \%$. O restante do percentual foi diversificado nas várias regiōes, predominando na região d.) deltóite e face anterior do ante-braço com o percentual de $12,5 \%$; face anterior da coxa e abdomem. Apresentando em mais de uma região: face anterior da coxa e deltóide, face anterior dit coxa e abdomem, e em todas as regiōes atingindo o percentual de $6,2 \%$ respectivamente.

A disparidade nos percentuais observados com o que relata a literatura, acreditamos que se deva ao desinteresse pelas(os) enfermeiras(os) na identificação do problema, pois, como foi constatado, o maior percentual incidiu no item "não observado".

Quanto aos critérios adotados para a escolha do local de aplicação da tera. pêutica insulínica, os autores classificaram como "insuficientes" conforme resultados analizados: $37,5 \%$ de acordo com as condiçōes do local da aplicação. $31,3 \%$ utilizam sistema de rodízio, $12,5 \%$ na face anterior do ante-braço e $12,5 \%$ de acordo com a preferência do paciente e $6,2 \%$ nos deltóides alternadamente.

No item que refere a providência tomada pela enfermeira(0) mediante a identificação da lipodistrofia insulínica, predominou com percentual de $81,2 \%$, : $t$ resposta de não aplicar na área lesada. O restante do percentual, isto é, 6,3\% informou "aplicar na área lesada". 
BORGES, R.C.C. e Colaboradoras - Um problema de enfermagem - A lipodistrofta insulínica. Rev. Bras. Enf.; DF, 31 : 252-258, 1978

$12,5 \%$ omitiram as respostas o que prejudicou a análise.

No item referente a orientação do paciente quanto ao local da aplicação de insulinoterapia $25 \%$ responderam que não orientam quanto ao sistema de rodízio e $\mathbf{7 5 \%}$ orientam o que verificamos. contradiz o comportamento dos profissionais, quando em questōes anteriores, concluimos que o maior percentual foi o não observado neste procedimento. A literatura preconiza o rodízio com a máxima na prevenção do aparecimento da complicação e se $75 \%$ dos colegas têm observado o rodízio no local da aplicação, faz-se necessário explicar porque ainda há 0 aparecimento destas lesōes.

Quanto ao método utilizado para controle da área da aplicação insulínica, constatou-se o maior percentual $43,7 \%$ cbservação do local de aplicação $37,5 \%$ não utiliza nenhum método, $12,5 \%$ se baseia na informação do paciente quanto a aplicação anterior, $6,3 \%$ atraves folha única.

De acordo com o critério de avaliação, proposta pelos autores o método preventivo da lipodistrofia insulinica é apli. cado com deficiência pelos enfermeiros pois apenas $37,3 \%$ deles utilizam o rodízio das áreas ou locais de injeção.

Nos pacientes identificados csm a lipodistrofia insulínica atingiu um percentual $40,0 \%$ nos deltóides e face externa na coxa respectivamente, $14,2 \%$ na face anterior do ante-braço, o que vem ratificar o que dizem os autores sobre a maior incidência de lipodistrofia e o aparecimento nos locais ou áreas de aplicação repetidas sem o devido rodízio.

Quanto ao tipo de insulina administrada nos pacientes portadores de lipodistrofia $60,0 \%$ estava sob tratamento com Insulina protamina Zinco associada à insulina regular, $21,1 \%$ insulina regular, 19,0\% Insulina Protamina Zinco.

\section{CONCLUSOES E} RECOMENDAÇOES

No presente estudo conclui-se que:

- Há ainda o aparecimento da lipo.. distrofia nos pacientes submetidos a terapêutica insulinoterápica subcutânea;

- As medidas controladoras e avaliadoras do local da aplicação insulínica são insuficientes;

- O estudo deverá ser ampliado com amostras significativas extensiva ao paciente ambulatorial, prosseguindo na exploração das causas lipodistróficas acompanhando o paciente desde o inicio do tratamento a fim de estabelecer paralelos para identificar melhor o problema.

Razão pela qual recomenda-se:

- As(os) Chefes do Serviço de Enfermagem:

- Implementação de instrumento controlador e avaliador das áreas e local da aplicação insulínica.

- Promoção de cursos de atualização sobre a assistência de enfermagem ao paciente diabético.

- As Chefes de Unidade:

- Despertar a Equipe de Enfermagem para os princípios fisicopatológicos que influenciam na aplicação insulinoterapia.

- Treinar a Equipe de Enfermagem que atua com pacientes diabéticos.

- Treinar o paciente diabético quanto ao autocuidado em todas as oportunidades surgidas.

- Participar na implementação do instrumento referido na primeira recomendação.

Identificação de Campo de Pesquisa Hospital

Setor 
BORGES, R.C.C. e Colaboradoras - Um problema de enfermagem - A lipodistrofta insulínica. Rev. Bras. Enf.; DF, $31: 252-258,1778$.

Identificação do paciente

Sexo

masculino ( )

feminino

Faixa etária:

$\begin{array}{rrrrll}- & 0 & a & 7 & ( & \text { ) } \\ - & 8 & \text { a } & 15 & ( & ) \\ - & 16 & \text { a } & 20 & ( & ) \\ - & 21 & \text { a } & 40 & ( & \text { ) } \\ - & 41 & \text { a } & 50 & ( & ) \\ - & + & \text { de } & 50 & ( & \text { ) }\end{array}$

Meio de controle da aplicação da insulina sub-cutânea

- Folha única

- prescrição de enfermagem ( )

- Mapa issulínico

- Não existe controle

Tipo de insulina prescrita

- NPH

- Regular

- Protamina zinco

- Mistura de insulina

IDENTIFICAÇĀO DO CAMPO DE PESQUISA

INSTNITUTO:

SETOR DE TRABALHO:

IDENTIFICAÇAO DO ENFERMEIRO:

Tempo de exercício Profissional:

- Menos de 2 anos

- de 2 a 7 anos

- de 8 a 13 anos

- acima de 13 anos

Formação Profissional:

- Apenas Graduação ( )

- Habilitaçāo

a) Enfermagem Médico Cirúrgica

b) Enfermagem em Saúde Pública

c) Enfermagem Materno Infantil

Cargo que Ocupa:

- Chefe do Serviço

- Supervisora

- Chefe de Setor

- Chefe de Unidade

- Enfermeira de Cabecelra 
BORGES, R.C.C. e Colaboradoras - Um problema de enfermagem - A lipodistrofia insulínica. Rev. Bras. Enf.; DF, 31 : 252-258, 1973.

\section{IDENTIFICAÇÃO DO PROBLEMA:}

O paciente portador de diabetes mellitus, submetido ao tratamento insulínico de manutenção apresenta lipodistrofia em que região?

- Glútea

- Face anterior da coxa

- Deltóide

- Abdominal

- Face anterior do antebraço

- Toda regiāo indicada

Qual o critério adotado para escolha do local para a aplicação insulínica?

- Preferência do paciente

- Condição no local de aplicação

- Indicação da área através do mapa

- sem orientação

- Somente na face anterior do antebraço

Qual a providência do enfermeiro mediante a observação de uma lipodistrofia insulínica?

- Aplicar somente na área lesada

- Não aplicar na área lesada

- Não levar em consideração a lesão

O paciente é orientado pelo enfermeiro quanto ao local de aplicação de insulina da seguinte forma:

- Sistema de rodízio do local ou área

- Não orienta quanto ao sistema de rodízio

Dos métodos abaixo indicados, assinale o que você utiliza para controle da área $\mathrm{e}$ local de aplicação insulínica subcutânea.

- Folha única

- Observação do local

- Mapa insulínico

- Não utiliza

- Informação do paciente . 